\title{
TRABALHO DE ANÁLISE INICIADO EM ESTÁGIO DE GRADUAÇÃO E OS ELEMENTOS ENCONTRADOS DE ACORDO COM A TEORIA
}

\author{
Maria de Fátima Oliveira ${ }^{1}$, Mônica Fujimura Leite ${ }^{2}$ \\ ${ }^{1}$ UNIVERSIDADE NORTE DO PARANÁ - UNOPAR. ${ }^{2}$ Núcleo de Apoio ao Desenvolvimento da Criança, no Programa Mãe \\ Parananense, Consórcio Intermunicipal do Médio Paranapanema - CISMEPAR. E-mail: mokileite@gmail.com
}

\begin{abstract}
RESUMO
Esta pesquisa discute sobre a possibilidade de atendimento analítico realizado dentro da universidade, sendo o problema de pesquisa "Existe a possibilidade de um trabalho de análise, sustentada e articulada com a teoria dentro da graduação?". Para tanto, tem como objetivo observar o desdobramento da prática de atendimento, a partir do referencial teórico da Psicanálise, desde os atendimentos na clínica escola, e sua continuidade na clínica particular, após a graduação do estagiário. Utiliza como metodologia um levantamento bibliográfico de textos de psicanalistas pós-freudianos, acerca dos dispositivos de uma análise, o qual foi articulado com fragmentos de casos clínicos. Como resultado, foi verificado que uma prática psicanalítica foi possível dentro do contexto de estágio, tendo esse trabalho se estendido para a clínica particular.

Palavras-chave: Psicanálise, Atendimento em Clínica-Escola, Estágio clínico, Formação em Psicologia Psicanalítica.

\section{ANALYSIS SERVICES INITIATED DURING AN UNDERGRADUATE PROGRAM PRACTICUM AND THE ELEMENTS FOUND ACCORDING TO THE THEORY}

\begin{abstract}
This research proposes to discuss the possibility of offering analytical services inside a university, by trying to answer the following research question: Is it possible to provide analytical work, supported and articulated by a theory, as part of a university undergraduate program? So, the objective is to observe the impact of a service practicum based on a Psychoanalysis theoretical framework, on the services provided at the school clinic and its continuation in the private clinic, after the student's graduation. The methodology was a bibliographic review of texts by PostFreudian psychoanalysts on analysis devices, a theory was articulated with fragments of clinical cases. As a result, it was verified that a psychoanalytical practice was possible in the context of the practicum, being this work extended to the private practice.
\end{abstract}

Key-words: Psychoanalysis, Clinical Service - School, Clinical Practicum, Psychoanalytical Psychology Education. 


\section{INTRODUÇÃO}

Ao se abordar um trabalho de análise na abordagem psicanalítica na clínica-escola e sua continuidade em clínica particular articulado com estágio acadêmico, tem-se a promoção de saúde mental na sociedade e o preparo profissional do aluno em Psicologia, entendendo-o um local apropriado para início do exercício profissional devido à seriedade de um ambiente controlado. Destacando que os usuários da clínica escola são oriundos em sua maioria de famílias com baixa renda e que não dispõe de recursos financeiros para bancar um tratamento psicológico particular; é nesse sentido que a clínica escola oferece suporte à sociedade ao oferecer um tratamento gratuito (SILVARES, 2000).

Com relação à formação do analista, Fonteles (2015) afirma que esta não se dá no contexto acadêmico, existem outros órgãos reguladores de analistas. Freud (1914/2006) coloca que só é possível aprender psicanálise tornando-se a si próprio um analisante (ou seja, tendo experiência com o próprio inconsciente). A formação do analista, a partir de Freud (1918/2006) é feita de três pilares: análise pessoal, supervisão e estudo teórico. A partir disso, Lacan (1967/2003) fundamenta a formação do analista dispensando a hierarquia, ao dizer que "o analista só se autoriza por si mesmo" (p. 248), a partir do testemunho de outros. Para isso, cria um dispositivo para a formação do analista, o passe, o qual permite ao psicanalista que no fim da análise o indivíduo passa de analisando a analista, a partir da enunciação de seu desejo.

Por outro lado, Ferreira (1998) traz que depois de Freud diversos psicanalistas e estudiosos versaram sobre a modalidade de transmissão em psicanálise e denominada por Lacan (1967/2003) de "Psicanálise em Extensão". De acordo com Almeida (2006) ela comporta o ensino aos demais públicos fora do dispositivo analítico, nestes moldes pode se falar em ensino da Psicanálise, na forma de cartéis, aulas, seminários, debates, palestras e cursos como meios de transmitir do trabalho de análise. Porém, o que viabiliza o tratamento psicanalítico é construção da transferência.

Dentre os dispositivos de uma análise, Freud (1912/2006) coloca a transferência como algo fundamental para o tratamento. Lacan trabalha sobre este conceito, denominando de "Sujeito Suposto Saber" o fenômeno no qual o paciente supõe que o analista sabe da verdade do inconsciente daquele. $O$ analista maneja a transferência de forma que o analisando passe a se intrigar e se interessar pelo próprio inconsciente, a partir do interesse do analista, o qual auxilia o paciente no desdobramento do discurso e na produção de significantes. Esses significantes terão novas atribuições através da transferência e segundo Freud (1912/2006), surge como uma resistência ao trabalho do analista, pois esses significantes podem trazer à consciência conteúdos recalcados que provocam sofrimento, os quais o paciente vai transferir ao analista. Essa ligação tem a ver com algumas das primeiras experiências afetivas vividas pelo paciente na infância (FREUD apud NASIO, 1999). Ao se referir sobre os significantes, Lacan (apud GODINO, 1988), diz que o paciente se liga ao analista de acordo com suas representações psíquicas, sendo elas, as imagos: paterna, materna ou fraterna servindo como elemento para a deteç̧ão da estrutura clínica do analisando.

Dentro da teoria psicanalítica existem três estruturas clínicas (FREUD apud OLIVEIRA, 2008): neurose, psicose e perversão. Estas resultam da elaboração da Castração no Complexo de Édipo, isto se dá a partir da instituição da linguagem, conforme traz Lacan (1957/2003). Ele também articula que o sujeito entra no mundo simbólico a partir do Complexo de Édipo, e a função paterna apresenta se como metáfora ao entrar no lugar do objeto de desejo da mãe (LACAN apud Oliveira, 1982).

Lacan (1956/2003) afirma que a condução técnica de análise determina que a função diagnóstica apresenta estruturas em diferentes formas de negação da castração. No neurótico, a castração é instalada através da perda do objeto no processo de elaboração da castração; porém, o neurótico não quer saber dela, então, recalca. Assim, a linguagem, no caso da neurose, se 
constitui através das metáforas, pelas quais se dão novos entendimentos. O material recalcado retorna na fala ou nos sintomas do paciente em forma de angústia, melancolia, desejo de um desejo insatisfeito, discursos contraditórios ou doenças no corpo sem causa aparente gerando indagações por parte do paciente de estrutura neurótica, sendo que a discussão do sujeito gira em torno da indagação "Quem Sou Eu”, (LACAN, 1957apud MACEDO, 2008, p. 20).

Já na estrutura clínica perversa a negação apresenta-se como desmentido, e o fetiche ocupa o lugar da castração, este sabe da castração, mas preenche-a com este objeto, de modo que a satisfação aparece no lugar da castração, (FREUD apud MACEDO, 2008). Diferentemente do psicótico, o qual recua diante da castração; logo, não há instalação da castração. O significante que interdita a satisfação é foracluído; com isso, o sujeito apresenta prejuízo em sua relação com a realidade externa conforme nos traz Oliveira (2008). No caso da estrutura clínica da psicose, tanto para Freud (1893), quanto Lacan (1956), a direção do tratamento é a estabilidade do quadro. A partir das repetições o paciente organiza o pensamento, ao construir uma metáfora (não paterna) pela via do discurso ou delírio. (LACAN apud GODINO, 1988). Tais sintomas e formas de defesa são escutados pelo analista através dos sonhos, atos falhos, chistes, atuações e acting-outs, inibições e angústias juntamente manifestações do inconsciente do analisando.

A técnica utilizada pela Psicanálise é a da associação livre. Nesta, o paciente deve ser incentivado a falar acerca do que escolher, sem importância ou que provoque mal estar (FREUD, 1913/2006). Do lado do analista, os conteúdos devem ser preservados pela atenção flutuante, pois ele não deve valorizar nada em detrimento de outras coisas e nem incorrer no erro de "doutrinar" o paciente conforme seus valores ou crenças, (FREUD, 1912/2006).

Nos chistes encontramos os trocadilhos de palavras ou dizer outra coisa no lugar do que o sujeito almejava dizer; de conotações verbais bem humoradas. Por meio destes, o paciente transforma, através de um processo mental, um conteúdo agressivo e difícil de ser conduzido em algo mais leve e agradável de ser dito (FREUD, 1905/2006), junto com o que é dito na análise a interpretação pode ser feita com pontuações, perguntas, um gesto do analista ou qualquer outra variante que determina intervenção, por exemplo, o corte. Este último refere-se à separação entre o significante e o significado pré-estabelecido pelo analisando, de modo que ele é surpreendido pela própria fala, (QUINET, 1991).

\section{METODOLOGIA}

Ao se fazer pesquisa em psicanálise trata-se da pesquisa na clínica, já que a psicanálise já é em si mesma um método de pesquisa, desenvolvida por Freud ao longo de sua obra para investigação dos fenômenos inconscientes (BIANCO, 2003). A partir disso, a presente pesquisa teve seu embasamento através dos estudos de caso, os quais segundo Moura e Nikos (2000) ocorrem através de fragmentos selecionados pelo analista através da clínica. A partir destes fragmentos o analista levanta uma hipótese a ser pesquisada, a qual será confrontada com a literatura que aborde o estado da questão até o momento. Poli (2008) acrescenta ao abordar que deve ser feita uma interpretação da hipótese levantada a partir das teorias anteriores, de modo que sejam produzidos novos conhecimentos.

A partir disso, o material utilizado para análise foi retirado do discurso de duas pacientes do sexo feminino, Jasmim, de vinte e seis anos e Tulipa, de cinquenta e dois anos, as quais estão em tratamento psicanalítico há 18 meses e que assinaram um termo livre e esclarecido autorizando a publicação do material. Para análise do material foi realizada uma revisão na literatura existente com o intuito de reunir dados sobre o assunto tratado, o que foi feito a partir das bases de dados LILACS e SCIELO e através de livros. Os assuntos pesquisados referem-se à temática da Abordagem e a Técnica Psicanalítica em Freud e Lacan, tais como a transferência, as estruturas clínicas, as manifestações do inconsciente e a técnica da associação livre. 


\section{RESULTADOS}

Nesses 18 meses de atendimento psicanalítico, durante as sessões, verificou-se que no discurso de uma histérica apresentam-se contradições, por exemplo, Tulipa: "Sou independente e nunca precisei que ninguém me desse nada e não me importo com a distância de minha família! (...) Quando eu era pequena nunca fiquei doente, dormia sozinha pela casa, acho que é por isso que meus pais me tratavam como se eu não existisse (...) tenho ressentimentos quando sou excluída dos eventos familiares" (SIC). Todavia, uma forma do analista intervir é interrogar. Sendo assim, interrogado a Tulipa sobre o que teria dela aí? Então, respondeu não saber. O que mostra nesse caso, é que Tulipa se contradiz quando diz ser independente, mas sofre ao ser excluída dos eventos familiares. Mas na sessão seguinte, a partir do mesmo discurso de independência, Tulipa acrescentou que sofria de abandono quando excluída. Então, a analista a interrogou novamente que, se é independente, então, por que sofre de abandono quando excluída? De modo que, a intervenção ocorre a partir da interrogação que tem efeito no paciente de ele próprio analisar sobre o que está dizendo. Deste modo, essa intervenção fez com que Tulipa repensasse sobre seu discurso de independência e buscasse se interrogar por que desde pequena foi tratada diferentemente entre suas irmãs? (SIC). E a análise se segue entre discursos por parte do paciente e ações interventivas por parte do analista.

A seguir, um exemplo de chiste no discurso de Jasmim quando ela parodiava sobre sua colega de sala de aula, que envolvia o modo como a colega se comportava durante as aulas; "Acha! Será que fulana não percebe que os outros veem que ela quer ser o que não é? Risos" (CIC). Neste momento houve interrupção e a analista perguntou "O que tem seu aí?". Jasmim "Alguém querendo ser o que não é?" nesse caso, pode-se perceber uma intervenção de corte e costura que ocorre no instante que o sujeito inconsciente precisa ser interrompido no sentido dele refletir sobre o que estava sendo falado e a paciente perguntou "Nossa! Já? Bem, tenho que pensar nisso." (SIC). Daí, na sessão seguinte, Jasmim disse que pensou durante a semana, não soube explicar, mas alguma coisa mudou dentro dela, (SIC).

Para finalizar, a formação do analista não consiste apenas na formação acadêmica, mas tornando-se um analisante por meio da experiência com o próprio inconsciente mediada pela análise pessoal, supervisão e estudo teórico, que pode ser realizado dentro de uma modalidade de ensino designado como forma de transmitir o trabalho psicanalítico através cartéis, aulas, debates, palestras, seminários, entre outros.

\section{DISCUSSÃO}

A relevância em explanar sobre as diferenças de estruturas psíquicas na clínica está em saber como manejar com cada uma delas, sendo que, com a estrutura neurótica o analista pode intervir e interrogar o sujeito, até que esse sujeito retorne para a consciência o material recalcado; tratamento que segue a linha de Freud (1893/2006) enquanto uma clínica para neurose, construída através da análise das histéricas.

$\mathrm{Na}$ estrutura da psicose, o analista não pode interrogar o sujeito, por que nesse caso, o tratamento possível é a estabilidade do quadro, pois o próprio paciente organiza o pensamento vindo a construir uma metáfora (não paterna) pela via do discurso ou delírio (LACAN apud GODINO, 1988); já na estrutura do perverso, o que lhe importa é somente seu desejo e não o do outro (FREUD apud MACEDO, 2008).

Então, os dois exemplos relatados iniciaram na clínica escola e estendeu-se para clínica particular. Para começar, houve o cuidado com a atenção flutuante, conforme Freud (1912/2006), pois o paciente associa livremente tudo que surgir em seus pensamentos e o analista não privilegia a escuta em conformidade com seus conteúdos particulares (GODINO, 1999). Sendo assim, o trabalho analítico consistiu em avaliar estrutura psíquica do paciente, para depois interrogar o sujeito inconsciente, assim como realizado corte e costura ao interromper a sessão. 
Um modo eficiente de intervir, que segundo Quinet (1991) a eficácia de uma intervenção começa quando se faz do corte no instante que o sujeito inconsciente precisa de uma interrupção para sugerir uma reflexão do que estava sendo dito naquele exato momento.

Mas trabalho analítico se sustenta a partir da transferência; e segundo Freud (1912/2006), pois surge como uma resistência ao trabalho do analista, pois esses significantes podem trazer à consciência conteúdos recalcados que provocam sofrimento, os quais o paciente vai transferir ao analista. Essa ligação tem a ver com algumas das primeiras experiências afetivas vividas pelo paciente na infância, sendo elas as imagos paterna, materna e fraterna, (FREUD apud NASIO, 1999).

Em relação à técnica da associação livre, o paciente deve ser incentivado a falar acerca do que escolher independente se fizer sentido, sem importância, (FREUD, 1913/2006). Neste momento, a ética de proteger as demandas reais do inconsciente do paciente, os quais não pertencem à verdade do inconsciente do analista, (FREUD, 1912/2006).

\section{CONCLUSÃO}

$\mathrm{Na}$ análise dos dois casos, alguns elementos se mostraram essenciais para o desdobramento do tratamento da clínica escola para a clínica particular do analista. Um deles foi a transferência. Esta compareceu no manejo do analista acerca do estabelecimento setting e do contrato do tratamento. $O$ analista manejou a transferência de forma que o analisando passasse a se intrigar e se interessar pelo próprio inconsciente, auxiliando-os, a partir da atenção flutuante, das pontuações e cortes, no desdobramento do discurso. Por outro lado, a partir da associação livre, ao permitir que o paciente falasse livremente sobre o que precisava, não houve um direcionamento da escuta nem no discurso do paciente.

Nesse sentido, pode-se concluir que foi possível a parte da formação do analista dentro do estágio em clínica da universidade, uma vez que houve o estabelecimento da transferência e a realização de um diagnóstico. A partir disso, foi possível notar um inicio de uma mudança de posição dos pacientes, de uma queixa dirigida a um suposto saber, para um questionamento a si próprio acerca de sua posição diante das coisas.

Para finalizar, importa lembrar que a formação do analista não consiste apenas na formação acadêmica, mas tornando-se um analisante por meio da experiência com o próprio inconsciente mediada pela análise pessoal, supervisão e estudo teórico.

\section{REFERÊNCIAS}

ALMEIDA, S.F.C. Transmissão da psicanálise a educadores: do ideal pedagógico ao real da (trans)missão educativa. Estilos da Clínica - Rev. da infância com problemas. v.11 n.21 São Paulo dez. 2006. Disponível em: http://www.revistasusp.sibi.usp.br/scielo.php?pid=S141571282006000200002\&script=sci_arttext. Acesso em maio de 2010.

BIANCO, Ana Carolina La. Sobre as bases dos procedimentos investigativos em psicanálise. USF, 2003. Disponível em: http://www.scielo.br/pdf/pusf/v8n2/v8n2a03. Acesso em agosto de 2016

FERREIRA, T. Freud e o ato de ensino. In: LOPES, E.M.T. A psicanálise escuta a educação. Minas Gerais: Autêntica, 1998. p.107-149.

FONTELES, Camila Santos Lima. Psicanálise e Universidade: uma análise da produção acadêmica no Brasil. 201f. 2015. Tese (Doutorado) - Instituto de Psicologia.

Disponível em: http://www.pospsi.ufba.br/Camila_Fonteles\%20(Tese).pdf. Acesso em agosto de 2015. 
FREUD, Sigmund. A Dinâmica da Transferência. In: Completas. Vol. XII. 1912/2006.
Artigos sobre Técnica. Obras Artigos sobre Técnica.Obras

FREUD, Sigmund. Sobre o início do Tratamento. In: Completas. Vol. XII. 1913/2006.

FREUD, Sigmund. Recomendações aos Médicos que exercem a Psicanálise. In: Artigos sobre Técnica. Obras Completas. Vol. XII 1912/2006.

FREUD, S. A História do movimento psicanalítico (1914). In: Edição Standard das Obras Completas de Sigmund Freud. A História do movimento psicanalítico, artigos sobre a metapsicologia e outros trabalhos. v. 14. Rio de Janeiro: Imago, 2006. p. 15-73.

FREUD, S. Sobre o ensino da psicanálise nas universidades (1918/). In: Edição Standard das Obras Completas de Sigmund Freud. Uma Neurose infantil e outros trabalhos. v. 17. Rio de Janeiro: Imago, 2006. p. 185-189.

GODINO, Gabas Antônio. A função do falo na Loucura. Campinas- S.P: Papirus, 1998

LACAN, Jacques. Proposição de 9 de Outubro de 1967 sobre o psicanalista da escola. In: Outros escritos. Rio de Janeiro: Jorge Zahar editor, 2003. p. 248-264.

MACEDO, Andressa Luiza C. Estruturas Clínicas, reflexões sobre o papel do Complexo de Édipo na formação das Estruturas. Universidade do Vale do Itajaí. Biguaçú, 2008.

MOURA, Ana. NIKOS, Isac. Estudo de caso, construção do caso e ensaio metapsicológico: da clínica psicanalítica à pesquisa psicanalítica. Pulsional Revista de Psicanálise, 2000, ano XIII, no 140/141, 69-76.

NÁSIO, J.D. Como trabalha um psicanalista? . Tradução: Lucy Magalhães. Revisão técnica, Marco Antônio Coutinho Jorge. Rio de Janeiro: Jorge Zahar Ed., 1999.

OLIVEIRA, Mariana Bacha Sales. O Conceito das Estruturas Psicanalíticas, Neurose E Psicose para a Psicanálise. Especialização em Psicanálise e Saúde Mental. UERJ, 2008. Acesso em: http://www.hce.eb.mil.br/rev/rev2008/conceitodasestrururas.pdf. Acesso em agosto de 2015.

POLI, Maria. Cristina. Escrevendo a psicanálise em uma prática de pesquisa. São Paulo: Estilos da clínica, 2008. Disponível em: http://pepsic.bvsalud.org/scielo.php?pid=S1415$71282008000200010 \&$ script=sci_arttext Acesso em agosto de 2016.

QUINET, Antônio. 4+1 Condições da Análise. Rio de Janeiro, Jorge Zahar Ed, 1991.

SILVARES, Edwiges Ferreira de Matos. Invertendo o caminho tradicional do atendimento psicológico numa clínica-escola brasileira. São Paulo, Estudos de Psicologia, 2000. Disponível em: http://www.scielo.br/pdf/\%0D/epsic/v5n1/a08v05n1.pdf Acesso em agosto de 2016. 